\title{
COVID-19 and importance of environmental sustainability
}

\author{
Naveen Kumar Arora ${ }^{1}$ Jitendra Mishra²
}

Published online: 13 May 2020

(c) Society for Environmental Sustainability 2020

A pandemic of unprecedented magnitude has rocked the mankind. As per the reports and research the sight of origin of the outbreak of this pneumonia-like disease has been identified as Wuhan, Hubei province of China (Wang et al. 2020). The respiratory illness was found to be associated with a novel coronavirus (COVID-19) which was later specifically named as "acute respiratory syndrome coronavirus 2" (SARS-CoV-2) by World Health Organization (WHO) (Lu et al. 2020). Millions of people around the globe have been infected, and several thousands have already perished. Apart from direct infections, almost every human on earth is going to be affected by this pandemic in one way or the other. The pandemic is going to inflict huge economic damages and the impact will be far-reaching, which is very difficult to assess as of now. In fact, this pandemic is going to have the biggest effect on mankind after the second world war catastrophe. Almost every country on the globe, except for a few island nations, have already been battered by the pandemic. However, looking at the magnitude of the situation, so far, no concrete scientific opinion is available to explain the original route of the transfer of coronavirus to humans. According to some reports, the origin of the deadly outbreak was found to be linked to Huanan Seafood Wholesale Market, a wet market in Wuhan, China (Salata 2020). Although the transfer route of the virus is not certain, one thing is assured that reservoir of coronavirus are some wild animals such as civets, bats, pangolins, etc. and most probably these are the source of this deadly virus to humans. As per World Livestock 2013 report of United Nation's Food and Agriculture Organization (FAO), $70 \%$ of the novel pathogens/diseases emerging in humans are zoonotic in nature. According to the available data consumption of animal meat

Naveen Kumar Arora

nkarora.bbau@gmail.com

1 Department of Environmental Sciences, School for Environmental Sciences, Babasaheb Bhimrao Ambedkar University, Lucknow, Uttar Pradesh 226025, India

2 DST-CPR, Babasaheb Bhimrao Ambedkar University, Lucknow, Uttar Pradesh 226025, India is increasing by the day, and some exotic wild animals have become part of the human platter; particularly in some parts of the world their demand is increasing as important portion of the diet. With most of the novel pathogens coming from animal sources this pandemic has raised several questions for mankind and its future.

In the year 2003, a respiratory illness known as severe acute respiratory syndrome (SARS) emerged in China. Like COVID-19, it was also caused by a coronavirus, named SARS-CoV. The virus affected over 8000 people worldwide and killed almost 800 . Early epidemiologic investigations indicated that masked palm civets (Paguma larvata) and horseshoe bats of the genus Rhinolophus, as natural reservoir of SARS-CoV (Wang 2007). Similarly, during 2013-2016, Ebola outbreak emerged in middle Africa and then spread to other countries in Western Africa resulting in 28,652 human infections and 11,325 deaths (WHO 2017). The transmission of the virus was sought to be a contact of humans with infected animals such as fruit bats, chimpanzees, gorillas, monkeys, forest antelope, or porcupines. Deadly influenza pandemics have emerged many times in recorded history. Data suggests that about $9 \%$ of the world's population is annually affected by influenza with up to 1 billion infections, 3-5 million severe cases, and 300,000 to 500,000 deaths each year (Clayville 2011), and many of these also have reservoirs in animals/birds.

In the past 50 years, globally the average amount of meat consumed per person has nearly doubled and hence production rate (of meat) is also growing much faster (Godfray 2018). FAO warned that a growing number of meat consumers will be leading to a heightened risk of new pandemics. ${ }^{1}$ Moreover, the risk is very high in various parts of Central Asia and Africa to spread the novel pathogens/pandemics as wildlife is one of the important sources of meat and income for the population in these regions. Man-animal conflicts, ever-increasing livestock cultivation (particularly near the wild habitats), intermingling of cultivated and wild animals, and cultivation of wild animals are important reasons for spread of the novel pathogens to humans. All these factors

\footnotetext{
${ }^{1}$ https://www.fao.org/newsroom/en/news/2007/1000660/index.html.
} 
relate to environmental instability which we have created on earth.

Rising meat demand, wet markets and global trade are only some of the directly visible reasons of the emergence of novel zoonoses in the human population. However, there are many important factors linked to the environment and the damage caused to it due to ever-increasing anthropogenic activities (Arora et al. 2018) which can be the root causes of pandemics such as COVID-19. Global warming and climate change, extreme levels of pollutants in the environment (soil, water and air), deforestation, fragmentation of natural environments, intensive farming, and globalization are the factors contributing to the emergence and spread of new wave of deadly pandemics. It is very clear that the spread of novel infectious diseases like COVID-19 is an outcome of a growing global population and overexploitation of natural environments. Deforestation and land use for intensive farming have significantly amplified the risk of zoonoses. Due to habitat loss and inclusion of exotic species in the platter, contact with wild animals and their body fluids has increased. As per reports about $60 \%$ of subtropical and $45 \%$ of tropical forests have vanished from the earth just because of human activities. The reduction of forest cover in such a high proportion is directly related to a higher risk of pandemics. For example, due to forest loss in West Africa, wild mammals including bats came in contact with humans and the Ebola outbreak emerged. Some studies indicate that "zoonotic spillover" are found to be more associated with threatened and endangered species that are increasingly being targeted for hunting and wildlife trade. These exotic species may carry new pathogens (of humans) that were not in our contact in the past and can play havoc as novel coronavirus is doing. Incidences of zoonotic spillover are increasing rapidly and mainly driven by environmental degradation, because humans are trespassing natural habitats and deliberately coming in contact with wildlife. Climate change that includes rise in temperatures, sea levels, change in $\mathrm{pH}$ of oceans, and altering patterns of rainfall/droughts are also impacting the incidences of zoonotic diseases. A slight increase in global temperature is expected to upsurge the risk of vector-borne diseases in new habitats/regions. For example, global temperature rise has resulted in migration of mosquitoes to new regions and this resulted in the transmission of Zika virus and dengue fever to new places where they were not previously reported. This clearly shows that global warming is resulting in the transfer of human pathogens (through vectors) to countries where they were not reported earlier. In some countries due to flooding events and rise in temperatures, incidences of vector-borne diseases such as malaria and dengue have also increased by $30 \%$ and $14 \%$ respectively (Struchiner et al. 2015; Boyce et al. 2016). Frequency of droughts has also increased due to climate change and this has resulted in increased dependency on meat from livstock and wild animals. Ever increasing levels of pollutants in the ecosystems is resulting in fast pace of mutations in microorganisms including human pathogens. Due to the unprecedented release of recalcitrant and xenobiotic pollutants, including radiations, microbial pathogens can mutate or evolve very quickly, resulting in the development of novel strains, which can be far more dangerous due to lack of immunity in the population against such microbes. Recently, Zhang et al. (2020) indicated that high-level of arsenic (III) load due to heavy metal pollution in water rapidly enhanced bacterial antibiotic resistance (BAR) and posed as a potential epidemiological threat to the public. There are numerous such examples of multiple drug resistant (MDR) microbes which are becoming more and more common now.

Humans are perturbing the habitats of wild animals and the normal cycle of pathogens and their hosts. In such circumstances, we are becoming more and more susceptible to new diseases. A human pathogen like Coronavirus is not fully understood till date and there can be several other strains of this virus (and many other viruses and bacteria) in nature or their reservoir hosts of wild animals which can be a matter of global health security in future as well. COVID19 pandemic is raising questions on our ongoing effort to improve the earth's environment. Frequent outbreaks of zoonotic diseases and their global spread through human to human contact have made it even more important to achieve the targets of sustainable development goals (SDGs). There should be more emphasis on adopting strict wildlife trade regulations and comprehensive measures for the protection of the natural environment. Most important is to rethink on holistic approaches for improving our relationship with the environment that will lead us towards sustainability. Agricultural sustainability and reducing dependency on animal products is one such example.

Also, there are some key lessons to be learned from COVID-19. These are related to our survival, preparedness, and responsibility towards nature which will lead to the control of future pandemics. Various types of shutdowns are proving to be effective not only in breaking the chain of infections but also healing of environment and ecosystems. Air and water pollution levels have come down in several regions of the globe and nature has started to reassert itself. Important is what we as mankind learn from this. Will we reduce the greenhouse gas emissions drastically, will the unnecessary travel be curtailed, will we reduce the dumping of pollutants in ecosystems to let the nature breathe, will we adopt sustainable agriculture practices, and stop disturbing the wild habitats. Most importantly, will all the stake holders including governments, organizations and individuals, unite together to fight the environmental pandemic which is going on since decades and resulting in loss of life and biodiversity. Sooner or later, the deadly coronavirus, and the most explosive pandemic in a century, will be tackled by 
vaccines or other methods, by the united efforts across the borders of countries and continents. But this is not the first novel pathogen to hit us and also not going to be the last one. A fresh perspective is required to address some key issues that we learnt from this pandemic. Mankind has to intercept the route causes of these pandemics in unison. The way to tackle such pandemics in advance is to go all out to achive the targets of environmental sustainability.

\section{References}

Arora NK, Fatima T, Mishra I, Verma M, Mishra J, Mishra V (2018) Environmental sustainability: challenges and viable solutions. Environ Sustain 1(4):309-340

Boyce R, Reyes R, Matte M, Ntaro M, Mulogo E, Metlay JP, Band L, Siedner MJ (2016) Severe flooding and malaria transmission in the western Ugandan Highlands: implications for disease control in an era of global climate change. Int J Infect Dis 214:1403-1410

Clayville LR (2011) Influenza update: a review of currently available vaccines. Pharm Therapeut 36(10):659-684

Godfray HCJ, Aveyard P, Garnett T, Hall JW, Key TJ, Lorimer J, Jebb SA (2018) Meat consumption, health, and the environment. Science 361(6399):eaam5324
Lu R, Zhao X, Li J, Niu P, Yang B, Wu H, Tan W (2020) Genomic characterisation and epidemiology of 2019 novel coronavirus: implications for virus origins and receptor binding. The Lancet 395(10224):565-574

Salata C, Calistri A, Parolin C, Palù G (2020) Coronaviruses: a paradigm of new emerging zoonotic diseases. Pathog Dis 77(9):ftaa006

Struchiner CJ, Rocklöv J, Wilder-Smith A, Massad E (2015) Increasing dengue incidence in Singapore over the past 40 years: population growth, climate and mobility. PLoS ONE 10(8):e0136286

Wang D, Hu B, Hu C, Zhu F, Liu X, Zhang J, Wang B, Xiang H, Cheng Z, Xiong Y (2020) Clinical characteristics of 138 hospitalized patients with 2019 novel coronavirus-infected pneumonia in Wuhan, China. JAMA 323:1061-1069

WHO (2017) World Health Organization. Ebola outbreak 2014-2016. Availble online http://www.who.int/csr/disease/ebola/en/

Zhang M, Wan K, Zeng J, Lin W, Ye C, Yu X (2020) Co-selection and stability of bacterial antibiotic resistance by arsenic pollution accidents in source water. Environ Int 135:105351

Publisher's Note Springer Nature remains neutral with regard to jurisdictional claims in published maps and institutional affiliations. 